\title{
Promovendo a autonomia e a motivação: o papel do conselheiro linguageiro
}

\author{
Walkyria Magno e Silva \\ Universidade Federal do Pará \\ walkyriamagno@gmail.com \\ Edirnelis Moraes dos Santos \\ Universidade Federal do Pará \\ di.letras@hotmail.com
}

\section{Resumo}

Este artigo visa a mostrar como conselheiros linguageiros podem fomentar a autonomia e a motivação de graduandos com entraves na aprendizagem de uma língua estrangeira (LE), ajudando-os a superá-los. Tal trabalho repousa sobre os arcabouços teóricos da autonomia, da motivação, das estratégias de aprendizagem e do aconselhamento linguageiro. Os dados foram coletados por meio de narrativas e cadernos de notas dos conselheiros com registros das sessões de aconselhamento. Foi constatado que o conselheiro pode exercer um papel significativo no desempenho de estudantes com dificuldades na LE.

Palavras-chave: Aconselhamento linguageiro. Autonomia. Motivação. Francês língua estrangeira.

\section{Abstract}

This text aims at showing how language advisers can help build autonomy and motivation of foreign language students with difficulties in learning, helping them overcome them. The research is based on theoretical issues, as autonomy, motivation, learning strategies, and language advising. Data were collected from three French students' narratives and their adviser's notes on advising sessions. Results show that the adviser can have a significant role in the performance of students with difficulties in learning a foreign language.

Keywords: Language advising. Autonomy. Motivation. French as a foreign language. 


\section{Introdução}

Os projetos de pesquisa intitulados "Aconselhamento linguageiro visando à autonomia e à motivação na aprendizagem de línguas estrangeiras", desenvolvido entre 2011 e 2013, e "Aprendizagem de língua estrangeira como um sistema adaptativo complexo: autonomia, motivação e aconselhamento linguageiro", em desenvolvimento desde 2013, têm por objetivo acompanhar as trajetórias de estudantes das licenciaturas em Línguas Estrangeiras (LE) (alemão, espanhol, francês e inglês) da Universidade Federal do Pará que apresentam dificuldades tanto na aprendizagem da LE quanto na busca de sua proficiência na língua que irão lecionar depois de graduados. Professores e alguns alunos mais adiantados do curso de Letras atuam como conselheiros linguageiros no âmbito da pesquisa.

Neste texto, mostraremos, a partir dos dados coletados, como um conselheiro de língua francesa (LF) conseguiu fomentar a autonomia e a motivação, ajudando os graduandos de francês que participaram do projeto a superar suas dificuldades durante o período de aconselhamento.

Em primeiro lugar, discorremos sobre os pressupostos teóricos envolvidos. Tratamos de questões de autonomia, motivação e estratégias de aprendizagem. Além disso, exploramos o conceito ainda pouco difundido da figura do conselheiro linguageiro (MOZZON; McPEARSON, 2007; RILEY, 1997), o qual, a exemplo de um conselheiro psicológico, procura levar o aconselhado a situar realisticamente seus impasses e a buscar os caminhos para solucioná-los.

Em seguida, apresentamos a metodologia adotada pelo conselheiro linguageiro, definindo o contexto da pesquisa e os sujeitos que dela participaram. Também descrevemos os materiais e os métodos utilizados pelo conselheiro para coletar dados com o objetivo de traçar o perfil dos estudantes e mostrar suas intervenções. Por fim, discorremos sobre suas intervenções de aconselhamento.

\section{Autonomia, motivação e estratégias de aprendizagem}

Nesta seção, apresentamos alguns aspectos acerca da autonomia, da motivação, das estratégias de aprendizagem e do 
aconselhamento linguageiro que serviram de suporte para a pesquisa aqui relatada.

Autonomia não é uma metodologia de ensino nem um conteúdo a ser estudado na sala de aula - é uma atitude diante do processo de aprendizagem (LITTLE, 1991). Segundo Benson (2001), ser autônomo compreende controlar três níveis diferentes de atuação, a saber: processos cognitivos, gerenciamento da aprendizagem e conteúdos da aprendizagem. Eles são intrinsecamente ligados, e um maior controle em um nível apoia o progresso nos outros dois.

Quanto ao controle sobre os processos cognitivos, muitos aprendentes desconhecem seus estilos predominantes de aprender e não exploram estratégias diversas para aprender de formas diferenciadas aquilo que estão estudando. No que diz respeito ao gerenciamento da aprendizagem, espera-se que o estudante saiba separar um tempo para estudar, determinar locais favoráveis a sua concentração naquilo que precisa fazer, privilegiar as ações de aprendizagem e resistir às forças detratoras. Quanto ao controle dos conteúdos, espera-se que o aprendente autônomo não se restrinja ao que lhe é ensinado em sala, espera-se que ele escolha alguns novos conteúdos e complemente aqueles previamente aprendidos, criando para si uma agenda paralela na qual expanda seus conhecimentos, seguindo seus próprios interesses.

Não se pode ensinar autonomia em uma sala de aula, mas se pode criar situações favorecedoras de autonomização. O ambiente de aprendizagem precisa ser psicologicamente seguro para que os alunos não tenham receio de questionar a metodologia proposta e para que eles possam dar suas sugestões. Além dessas atitudes, eles precisam ser estimulados e apoiados para refletir sobre os aspectos cognitivos, como descobrir seus estilos e estratégias preferenciais, e afetivos, como, por exemplo, superar o nervosismo.

Diz Ushioda (1996) que um aprendente motivado é também um aprendente autônomo. Tendemos a concordar nesse aspecto, compreendendo que autonomia e motivação são construtos que alimentam um ao outro, engendrando uma aprendizagem bem-sucedida. Assim, mantendo a motivação ativada, os estudantes tendem a se tornar mais autônomos e a buscar maiores conhecimentos a respeito daquilo que os motiva. 
A questão maior a respeito de motivação é sua natural flutuação e variabilidade. Dörnyei (2000/2011, p. 209) define motivação como

\section{[...] um estado alerta cumulativo dinamicamente mutante em um indivíduo que começa, direciona, coordena, amplifica, termina e avalia os processos cognitivos e motores por meio dos quais vontades e desejos iniciais são selecionados, priorizados, operacionalizados e desempenhados (com ou sem sucesso).}

Nesse conceito, podemos claramente identificar o papel do sujeito como gerenciador de todo o processo motivacional. Vemos ainda a dinamicidade dessa motivação, dependente de inúmeros fatores, e sua qualidade de ser mutável, ou seja, variável. No desenrolar do processo motivacional, ações por vezes simultâneas são assumidas pelo sujeito na tentativa de alcançar o sucesso, o que não é garantido, embora seja favorecido pelo processo motivacional.

Por isso, estratégias de aprendizagem são ações adotadas por alunos de uma língua estrangeira para melhorar sua própria aprendizagem. Oxford (1990, p. 8) define-as como "ações específicas executadas pelos aprendentes para tornar a aprendizagem mais fácil, mais rápida, mais prazerosa, mais autodirigida, mais eficaz e mais transferível para outras situações". 1

Segundo essa autora, pode-se dividir as estratégias de aprendizagem em duas classes principais: diretas e indiretas. A primeira envolve a utilização da língua e é composta por três grupos de estratégias: (1) de memória, que ajudam no armazenamento e na recuperação das novas informações; (2) cognitivas, que permitem a compreensão e a produção na língua alvo de diferentes maneiras; (3) de compensação, que tornam possível o uso da nova língua apesar da falta de vocabulário ou de estruturas gramaticais.

A segunda classe de estratégias, as indiretas, contribui para administrar o processo de aprendizagem sem envolver diretamente a língua. Elas são divididas em: (1) metacognitivas, que ajudam o estudante a coordenar, a planejar e a avaliar seu processo de aprendizagem; (2)

1 "Specific actions taken by the learner to make learning easier, faster, more enjoyable, more self-directed, more effective, and more transferrable to new situations." 
afetivas, que o auxiliam a regular suas emoções, motivações e atitudes, permitindo assim o controle psicológico que favorecerá a utilização das outras estratégias; (3) sociais, que possibilitam ao aprendente aprender por meio da interação com os outros indivíduos ou grupos envolvidos nesse processo.

As estratégias diretas e indiretas são igualmente importantes no processo de aprendizagem e seus subgrupos apoiam uns aos outros. $\mathrm{O}$ uso das estratégias apropriadas na aprendizagem de uma LE resulta em um melhor desempenho da capacidade linguísticae maior autoconfiança da parte do aprendente. Os indivíduos têm de deixar de ser passivos na sua aprendizagem, devido geralmente a uma cultura imposta pelo sistema educacional.

Apenas mostrar aos aprendentes que existem estratégias não é o bastante, é preciso que eles queiram assumir maior responsabilidade na própria aprendizagem. As estratégias de aprendizagem não são sempre observáveis nos aprendentes, e é aí que o conselheiro começa seu trabalho, ao demonstrar, exercitar e propor diferentes possibilidades ao aprendente. Após certo uso e prática, as estratégias, como qualquer outra habilidade ou comportamento, tornam-se automáticas, e é isso que se almeja.

\section{Aconselhamento linguageiro}

O aconselhamento linguageiro implica uma nova visão a respeito dos indivíduos que buscam o aconselhamento e daqueles que se dispõem a fazê-lo. Em virtude de ser um campo recente de pesquisa no ensino-aprendizagem de línguas, algumas perguntas encontram-se abertas: “o que é" e "como" se faz o aconselhamento? (RILEY, 1997).

Conforme Riley (1997), o conselheiro é a pessoa que ajuda o aprendente: (1) a tomar suas próprias decisões, tornando-o consciente de suas representações, crenças e atitudes com um olhar mais acurado sobre o processo de aprendizagem; (2) a identificar seu estilo de aprendizagem, suas preferências, suas necessidades e objetivos de aprendizagem de línguas; (3) a escolher atividades, técnicas e materiais apropriados; (4) a elaborar um programa de aprendizagem, monitorar e avaliar seu progresso.

Dentro de um centro tido como modelo na Europa, MozzonMcPherson (2007) descreve a figura do conselheiro linguageiro como gerador de sinergia no processo de aprendizagem dos alunos. Nesse 
contexto, os conselheiros dominam não só a língua estrangeira em foco como principalmente os instrumentos necessários para criar empatia com os alunos aconselhados de forma que eles se sintam à vontade para discutir suas questões a respeito da aprendizagem da LE. Normalmente, é preciso duas ou três sessões de aconselhamento para que se crie essa ligação de confiança entre conselheiro e aconselhado.

Segundo Mozzon-McPherson (2007), as funções dos conselheiros linguageiros são:

Oferecer orientação adequada e clara e apoio para que os alunos trabalhem autonomamente;

- ajudar a instituição a prover oportunidades de aprendizagem de línguas apropriadas;

- monitorar os padrões de aprendizagem dos usuários do serviço e prover retorno relevante e eficaz;

- monitorar a disponibilidade de recursos disponíveis em relação às necessidades dos usuários;

- facilitar a habilidade dos aprendentes em tornaremse mais proficientes por meio de um melhor entendimento do seu próprio processo de aprendizagem;

- ouvir as necessidades dos aprendentes e provocar conversas sobre a língua e sobre a aprendizagem.

Após algumas leituras preliminares a respeito do desempenho de conselheiros linguageiros em outros projetos, especialmente em Vieira (2007), o grupo de pesquisa tomou como diretrizes as seguintes ações: 1) desenvolver uma consciência crítica; 2) desenvolver a colaboração; o diálogo e a reflexão; 3) estimular a reflexão sobre a aprendizagem individual (comparar-se a si próprio no passado e não aos colegas que sabem mais); 4) promover a construção pessoal do conhecimento, valorizando a individualidade do caminho do desenvolvimento linguageiro; 5) apoiar o processo de reflexão na/para a ação; e 6) documentar o processo de desenvolvimento.

A sequência de procedimentos para apoiar o desenvolvimento linguageiro dos aconselhados foi idealizada da seguinte forma: em primeiro lugar, estabelece-se uma tomada de posição para analisar a experiência pessoal de aprendizagem de LE e identificar uma área de preocupação pessoal do aconselhado; em seguida, planeja-se proativamente, para 
enfrentara a área de preocupação pessoal; o terceiro passo é exercer uma intervenção monitorada, agindo e refletindo, coletando e analisando informações por meio de observação, notas de campo, narrativas, listas de checagem avaliativas, questionários, análise do trabalho dos alunos, entre outros materiais produzidos durante o aconselhamento.

Como último passo, dá-se a avaliação e o replanejamento, levantando os pontos positivos e negativos da intervenção, planejando uma nova intervenção para o mesmo problema ou, se ele estiver resolvido, devese planejar uma intervenção para um novo problema. Nesta última fase, é fundamental celebrar as pequenas ou grandes vitórias, pois isso valoriza o sucesso dos aprendentes, contribuindo assim para a melhoria da sua autoestima.

\section{Papel do conselheiro linguageiro: metodologia e intervenções}

Nesta parte do texto apresentamos a metodologia adotada pelo conselheiro linguageiro, definindo o contexto da pesquisa, os sujeitos que dela participaram, além de mostrar como se dá a seleção dos aconselhados, isto é, dos alunos com dificuldades na aprendizagem da LE. Também expomos os materiais e os métodos utilizados pelo conselheiro para coletar dados com o objetivo de traçar o perfil dos estudantes e suas intervenções.

No projeto de pesquisa, os alunos acolhidos apresentam dificuldades na aprendizagem de uma LE, cuja licenciatura é oferecida pela Faculdade de Letras Estrangeiras Modernas da UFPA (FALEM), com habilitação em alemão, espanhol, francês ou inglês. Alunos com dificuldades de aprendizagem na LE de sua graduação procuram espontaneamente o grupo de conselheiros ou são a ele encaminhados por seus professores ou colegas.

O início do processo de aconselhamento dá-se quando o conselheiro entra em contato com os graduandos selecionados e tem uma primeira conversa a respeito do funcionamento da proposta de "aconselhamento linguageiro" para esclarecer que se trata de um projeto de pesquisa e que sua identidade será preservada, assim como as identidades de todas as pessoas por ele referidas. É neste momento que o conselheiro explica aos aconselhados quais os próximos passos:

- fornecimento de informações básicas (nome, $e$ mail, número de matrícula); 
- realização de Teste de Estilo de Aprendizagem Preferencial (Teap) (traduzido de Felder; Soloman);

- preenchimento do Inventário de Estratégias de Aprendizagem de Línguas (Ieal) (OXFORD, 1990);

- $\quad$ produção de uma narrativa de aprendizagem da língua estrangeira;

- reflexão e conversa com o conselheiro sobre as principais dificuldades de aprendizagem da língua estrangeira em que se gradua;

- $\quad$ elaboração de plano(s) de ação para tentar resolver essas dificuldades;

- execução do plano de ação, adequando-o e modificando-o de acordo com a negociação conduzida com o conselheiro.

Um recurso utilizado pelos conselheiros é o caderno de notas, no qual são anotadas informações prestadas pelos alunos nas sessões de aconselhamento. Tais informações são importantes, pois nos permitem traçar seus perfis e elaborar um plano de ação que atenda às suas necessidades.

O conselheiro de língua francesa (LF) -doravante C1 -nos períodos da pesquisa, isto é, nos primeiros semestres de 2011 e 2014, cursava Letras - Língua Francesa na mesma universidade. Ele possui também graduação em Letras - Hab. Língua Portuguesa pela Universidade Federal do Pará e Mestrado em Letras/Linguística na mesma universidade, além de atuar como professor voluntário do Projeto de Extensão Português Língua Estrangeira da Universidade Federal do Pará.

No primeiro semestre de 2011, C1 selecionou dois estudantes do curso de francês que ingressaram em 2009 para serem seus aconselhados, os quais serão designados pelas letras A1 e A2. Em 2014, a escolha do aconselhado ocorreu pelo fato de um estudante iniciante (doravante A3) da graduação em língua francesa ter procurado auxílio na Base de Apoio à Aprendizagem Autônoma $\left(\mathrm{BA}^{3}\right)^{2}$ já na segunda semana de aula, pois pensava em desistir do curso.

De um lado, A1 e A2 continuavam regularmente matriculados, não estavam atrasados e não foram reprovados em nenhuma disciplina.

${ }^{2} \mathrm{~A} \mathrm{BA}^{3}$ é um laboratório da FALEM. 
Eles já tinham terminado o quarto e último nível de língua francesa, ${ }^{3}$ mas demonstravam muita insegurança quanto à proficiência da língua, sobretudo no que diz respeito à produção oral. Tanto A1 quanto A2 tinham aulas com $\mathrm{C} 1$. A3, calouro no curso, ainda estava se adaptando ao ritmo da vida universitária e frequentemente se perguntava sobre o motivo de ter escolhido a licenciatura em língua francesa, demonstrando incerteza em ter escolhido a carreira certa para si.

Um obstáculo constante é a falta de tempo para estabelecer sessões regulares de aconselhamento. Em virtude desse fato, $\mathrm{C} 1$ perguntou se ele poderia ser conselheiro em tempo integral, isto é, se $\mathrm{C} 1$ poderia exercer o aconselhamento nos momentos em que percebia ser oportuno e também quando seus aconselhados sentissem necessidades, uma vez que eram colegas de classe e se encontravam regularmente. Com A3, as sessões se deram em horários preestabelecidos, às 14 horas, às terças e quintasfeiras na $\mathrm{BA}^{3}$.

Não vamos descrever aqui detalhadamente todas as intervenções do conselheiro linguageiro - nem haveria espaço para isso -, mas daremos uma visão geral do papel que ele pode ter ao aconselhar alunos com dificuldades na aprendizagem de LE, sobretudo em relação às práticas que levaram em conta a formação teórica já apresentada, para ajudá-los a superar os obstáculos enfrentados.

No primeiro encontro, C1 explicou como funcionava a proposta de aconselhamento para que os aconselhados ficassem cientes do desenrolar do processo e pudessem optar por participar da pesquisa ou não. Logo, o conselheiro esclareceu que aquilo que fosse falado nos encontros de aconselhamento ficaria somente entre os envolvidos, mas que precisaria compartilhar algumas informações nas reuniões do projeto, ressaltando que todos os conselheiros seguem o mesmo princípio em relação ao sigilo nas informações apresentadas.

Os três aconselhados fizeram a mesma pergunta, a exemplo do questionamento de A3: "Posso falar de 'coisas' além da aprendizagem do francês, coisas mais pessoais, sobre dificuldades em casa, sobre os professores? Porque isso de certa forma prejudica a minha aprendizagem" (Caderno de notas de $\mathrm{C} 1$ ). Após a resposta positiva de $\mathrm{C} 1$, concordaram em

\footnotetext{
${ }^{3}$ No currículo seguido por essas alunas, ter concluído o Compreensão e Produção em Francês 4 indica que já foram cumpridas 480 horas de instrução em língua francesa.
} 
participar da pesquisa. Neste ponto, observamos como é importante haver uma relação de confiança entre conselheiro e aconselhado para que o processo de aconselhamento flua. Além disso, é imprescindível que o primeiro nunca falhe em seu compromisso em manter o sigilo.

Depois dessa etapa, C1 solicitou os dados acadêmicos dos aconselhados para verificar o percurso que eles haviam feito no que concerne à aprendizagem da LF. Em seguida, A1 e A2 tiveram acesso ao Teap e ao Ieal para serem preenchidos em casa e se comprometeram a escrever a narrativa de aprendizagem e entregar posteriormente. Entretanto, somente A1 apresentou o Ieal respondido e a narrativa de aprendizagem; A2 comprometeu-se a entregá-los antes do fim do primeiro semestre de 2011. A3 na época estava cursando a disciplina "xxx", na qual os estudantes são solicitados a preencher os referidos testes e eles foram cedidos pelo professor da disciplina para o conselheiro.

A1 teve uma sessão que durou duas horas para esclarecimento do resultado do questionário Ieal. $\mathrm{O}$ aconselhado identificou-se com o que foi mostrado no inventário e concordou que precisava melhorar em alguns pontos, precisava saber usar as estratégias a seu favor, precisava saber administrar melhor suas emoções, pois o fato de ele não estar sabendo gerenciá-las estava prejudicando sua aprendizagem.

Os aprendentes, em momentos distintos, foram incentivados a pensar em suas trajetórias na graduação de língua francesa. Os aconselhados A1 e A2 relataram as dificuldades que tiveram em aprender a LF, pois vinham do curso de língua inglesa e isto afetava, na opinião deles, o entendimento da nova língua. Ao escutar esse relato, $\mathrm{C} 1$ interveio e disse que eles não deveriam ver a proficiência em inglês como um obstáculo, mas deveriam aproveitar as estratégias que usaram para aprender inglês para se apropriar do francês. Nessa ocasião, o conselheiro ajudou os aconselhados a reconfigurarem suas crenças e atitudes (RILEY, 1997), além de estimular o uso de estratégias metacognitivas (OXFORD, 1990).

$\mathrm{Na}$ atitude de $\mathrm{C} 1$, percebemos uma tentativa de conscientizar os aconselhados a transferirem estratégias em prol da aprendizagem da nova língua, pois, como dito anteriormente, nem sempre os aprendentes conseguem fazer isso naturalmente. Este é o momento propício para o conselheiro intervir, visando a demonstrar que, como qualquer outra habilidade ou comportamento, é importante tomar certas atitudes para alcançar aquilo que se almeja, principalmente aproveitando estratégias já adquiridas. 
Os três aconselhados deram ênfase à dificuldade de falar em francês, ou seja, a não proficiência em se expressar oralmente na línguaalvo, pois se comparavam aos colegas que possuíam um nível de língua um pouco mais avançado, como é evidente na narrativa de aprendizagem de A1:

No segundo ano a turma ficou eclética. Alunos repetentes entravam na turma fazendo com que houvesse uma diferença muito grande entre o nível de língua dos alunos. Isso me desmotivou. Achava que eu não conseguia acompanhar a turma (A1).

Ainda quanto à dificuldade de falar, A3, aluno iniciante, sentia-se angustiado por não conseguir comunicar-se em francês. Para tentar superar essa angústia, conselheiro e aconselhado discutiram formas que poderiam ser utilizadas para treinar em casa, tais como ensaiar os diálogos do manual e gravar para trazer nos próximos encontros em que C1 poderia verificar a pronúncia e ajudá-lo a melhorar. Nesse sentido, está-se propiciando um trabalho autônomo, isto é, além da sala de aula, pois o aprendente, que não possuía técnicas para aprender sozinho, poderá estudar de forma independente, sabendo que pode consultar alguém mais proficiente depois.

C1 tomou cuidado para que o aconselhamento não incomodasse seus aconselhados, que eram colegas de classe, pois não queria passar a impressão de os estar monitorando o tempo todo. Essa estratégia deu certo, pois o conselheiro aproximou-se e manteve uma relação de confiança e apoio com seus aconselhados. Com A3, C1 teve 14 encontros, menos do que o previsto devido a compromissos do aconselhado e outros eventos que impossibilitaram as sessões. Contudo, isso não prejudicou o andamento do aconselhamento, uma vez que outros meios foram usados, pois, mesmo quando não podia comparecer, A3 com frequência utilizava mensagens de texto para avisar e treinar o francês escrito:

\section{A3: Salut C1!}

Excuze-moi mais aujourd'ui je ne vais pas au cours. J'ai mal á la tetê, je vais dejuner chez moi et après je vais dormir un peu pour ameliorer.

Mercredi avoir cours? Parce que je ne sais pas c'est oui ou non! Tu pourrais me dit?

Ah! Tu pourrais aussi me dit ce je te écrit correctement? 


\begin{abstract}
Merci
à prochaine

[...]

C1: [...] je suis très fière de toi et de ton niveau de français.Tu as super bien écrit, même s'il y quelques fautes. Demain, il n'y aura pas cours!! On se voit jeudi et repose-toi bien! ${ }^{4}$
\end{abstract}

Neste exemplo, notamos não somente a tentativa do aconselhado em escrever na LE alvo, mas também o conselheiro exercendo seu papel de valorizador do desenvolvimento da aprendizagem do aconselhado, pois é imperativo mostrar ao aconselhado que os passos dados por ele, embora pareçam pequenos, são enormes em busca da proficiência em língua francesa.

Nos meses de maio e junho de 2011, A1 e A2 tiveram de apresentar pelo menos três seminários distribuídos entre as disciplinas do semestre. Assim, os aconselhados viram-se em situações em que deveriam expor-se oralmente, colocando à prova o ponto fraco mencionado por eles. Nesse momento, C1tranquilizou-os, dizendo que não deveriam preocuparse, pois se eles se preparassem com antecedência teriam um bom desempenho nas apresentações e que o conselheiro poderia auxiliá-los na preparação da exposição.

A1 fez um esquema dos seminários e apresentou para $\mathrm{C} 1$, sempre hesitando quando não sabia a pronúncia de uma palavra ou quando não sabia como eram ditos alguns termos em francês. A reação de $\mathrm{C} 1$ era: "Tenta pronunciar", "Tenta dizer de outra forma, da maneira que tu sabes". Ao agir assim, C1 claramente exerceu o quinto ponto do elenco de procedimentos rotineiros do grupo de conselheiros, i.e., apoiou o processo de reflexão tanto na quanto para a ação.

Quanto à A2, ele consultou $\mathrm{C} 1$ para perguntar: "O que tu achas d'eu fazer isso?", "Será que vai ficar legal assim?". O conselheiro respondeu: "Tu te sentes à vontade para explicar dessa maneira?". A2

\footnotetext{
${ }^{4}$ A3: Oi C1! Desculpe mas hoje eu não vou à aula. Eu tenho dor de cabeça, eu vou almoçar em casa e depois eu vou dormir um pouco para melhorar. Quarta-feira haverá aula? Porque eu não sei se sim ou não! Tu poderias me dizer? Ah! Tu também poderias me dizer se eu escrevi corretamente? obrigado! Até a próxima! C1: [...] Eu estou muito orgulhoso de você e de seu nível de francês.Tu escreveste muito bem, mesmo se há alguns erros. Amanhã, não haverá aula! Vejo você quinta-feira! Descanse bem!
} 
afirmou que "sim". C1 replicou: "Não te preocupa se tu não falas francês com sotaque francês! Tu tens a tua própria maneira de falar francês, um francês com sotaque paraense, é com ele que tu tens que tentar te comunicar". O aconselhador lembrou que havia escutado certa frase de uma das suas professoras da graduação: "Tu as ton français à toi" (tu tens o teu próprio francês). Esta frase marcou sua aprendizagem, pois ela acreditava que deveria falar "perfeitamente" como um francês e só agora compreendia de maneira apropriada aquela observação de sua professora.

C1 pôde assistir aos seminários de seus aconselhados e ambos tiveram um bom desempenho em suas apresentações. Eles receberam elogios de seus colegas - e de seu conselheiro também - pela exposição dos trabalhos. Os colegas de classe fizeram até mesmo comparações com seminários anteriores, mostrando que eles haviam progredido bastante na produção oral em língua francesa.

Na noite de uma quinta-feira do mês de junho de 2011, C1 recebeu uma mensagem de texto em seu celular enviada por A2 perguntando sua opinião sobre a possibilidade de desistir de uma disciplina da graduação. C1 foi surpreendido pela mensagem e teve de pensar bastante em como proceder neste caso. As mensagens trocadas entre A2 e C1 foram:

A2: $O q$ vc acha? Quero desistir da disciplina do prof. X. $n$ vou conseguir passar. além d ter mta falta, falta 2 trabalhos $p$ fazer fora o seminário $q$ n estudei. vai sair uma coisa horrível. (19:21h)

C1:Bom, eu tenho certeza q não deves desistir. [...] Pensa que semana $q$ vem terás mais tempo $p /$ tentar fazer os trabalhos $q$ estão faltando! Não teremos mais seminário p/ preparar, será uma semana mais light! (-)(19:40h)

A2: Caramba! ah mas tu apresentas bem trabalho do seminário. já eu ... (19:42h)

C1: mas temos muito mais a perder desistindo do q tentando! (-) (19:44h)

A2: É isso q eu pensei ainda agora. Mas esses trabalhos..e já pensou? ele reprovando td mundo!rsrsr (19:49h)

C1: hauhauhau! Já pensou! :P mas não desiste, não. Tenta manter a calma q no final alguma coisa sai! @)(19:55h)

A2:Obrigada pelos conselhos. Vou até o fim p ver no q vai dar... boa noite! (22:23h) 
A troca de SMS teve um bom efeito, pois A2 não desistiu da disciplina e apresentou os trabalhos finais, obtendo aprovação. Esse fato pôde beneficiar o aprendente de várias maneiras: aumentando sua autoestima, valorizando seu esforço pessoal para atingir seus objetivos e ensinando-o a estudar com mais eficácia ao refletir sobre o que realizou para obter sucesso. Vê-se neste episódio a importância do papel de C1 na manutenção da motivação de A2. Como visto na seção inicial deste texto, a motivação não é estável nem garante o sucesso de um processo, mas ela é fundamental para que se mantenha o rumo em processos longos, como o da aprendizagem de uma nova língua (DÖRNYEI, 2011).

Em se tratando de desistência, como dito anteriormente, A3 já na segunda semana do curso de francês pensava em desistir por vários motivos. C1 notou que essa indecisão em permanecer no curso tinha alguns fatores:

1 - ter escolhido Letras para futuramente prestar vestibulinho para o curso de Jornalismo;

2 - ficar abalada com a metodologia do professor $X$, o qual já no primeiro dia de aula disse que para cursar francês é preciso ter uma inteligência superior, que muitos ali não chegariam até o fim do curso (Caderno de notas de C1).

O segundo item destacado foi tema de várias sessões de aconselhamento, pois A3 entrou bastante engajado no curso, mas esta frase abalou sua motivação. A disciplina ministrada pelo professor $\mathrm{X}$ é chamada de "Língua Francesa I", que divide a carga horária com o professor Y, cada um coordenando uma semana de aula. $\mathrm{C} 1$ percebeu que quando o professor $\mathrm{X}$ dá aula, A3 fica abalado; quando é a semana do professor Y, A3 comparece mais tranquilo aos encontros.

Como C1 já havia cursado disciplinas com os professores citados, tentou conscientizar A3 ao exprimir que "cada professor tem sua personalidade e que ele deverá aprender a lidar com isso. Os alunos há mais tempo no curso já conseguiram entender ou aprenderam a compreender esse tipo de assertiva como um desafio, isto é, o professor $\mathrm{X}$, na verdade, quando diz que um aluno não vai conseguir, ele quer que tu te esforces mais para mostrar que ele estava errado" (Caderno de notas de C1).

Neste relato, ressaltamos duas atitudes do conselheiro: (1) saber ouvir com ética aquilo que é dito pelo aconselhado em relação aos professores, mantendo em segredo a identidade dos docentes nas reuniões; 
(2) tentar encontrar uma saída para que A3 não bloqueasse sua aprendizagem devido a uma fala infeliz do professor $\mathrm{X}$. Ao final do semestre, A3 parecia ter superado o obstáculo com o professor de língua, porém sentiu dificuldades com as disciplinas teóricas do curso. Isso foi superado, e A3 terminou o semestre com êxito em todas as disciplinas e motivado para enfrentar o segundo semestre.

Assim, podemos ver que o investimento de $\mathrm{C} 1$ no aconselhamento de A1, A2 e A3 provou ter sido muito bem aproveitado, de forma que é possível apontar bons resultados no papel do conselheiro linguageiro em promover tanto autonomia quanto a motivação dos aconselhados, além de ajudá-los na aprendizagem da LE. É notável também o desenvolvimento de habilidades do conselheiro linguageiro para provocar reflexões e atitudes autônomas com o intuito de não prover respostas prontas, mas de encorajar a busca de um caminho a seguir.

\section{Considerações finais}

Expusemos como o conselheiro de língua francesa desenvolveu suas próprias habilidades e intervenções no processo de aconselhamento linguageiro para se aproximar dos alunos, melhorar as formas de aconselhar e favorecer a autonomia, a motivação e a aprendizagem da LE, demonstrando aproveitar as leituras teóricas do projeto "Aconselhamento linguageiro" para direcionar sua forma de intervir nas dificuldades apresentadas pelos estudantes de língua francesa.

Ressaltamos que os resultados do aconselhamento linguageiro são positivos, logo, é importante que esse tipo de proposta seja expandido, posto que o conselheiro tem um papel significativo no desempenho dos aconselhados, tendo em vista que suas intervenções buscam não somente melhorar a aprendizagem da LE, mas também conhecer mais a fundo os obstáculos dos alunos, propiciar momentos de reflexão e apoiar a construção do indivíduo como estudante de LE. 


\section{Referências}

BENSON, Phil. Teaching and researching autonomy in foreign languages learning. Harlow, England: Pearson,2001.

DÖRNYEI, Zoltán. Motivação em ação: buscando uma conceituação processual da motivação de alunos. In: BARCELOS, Ana Maria F.(Org.). Linguística aplicada: reflexões sobre o ensino e aprendizagem de língua materna e língua estrangeira. Tradução: André Monteiro Diniz e Walkyria Magno e Silva. Campinas: Pontes, 2001. p. 199-236..

FELDER, Richard; SOLOMAN, Barbara. Index of learning styles questionnaire.

<http://www.engr.ncsu.edu/learningstyles/ilsweb.html >.Acesso em: $14 / 08 / 2011$.

LITTLE, David. Autonomy: definitions, issues and problems. Dublin: Authentik, 1991

MOZZON-McPHERSON, Marina. Supporting independent learning environments: an analysis of structures and roles of language learning advisers. System, v. 35, n. 1, p. 66-92, 2007Special Issue on Counseling in Language Learning Settings..

OXFORD, Rebecca. Language learning strategies: what every teacher should know. Boston: Heinle \& Heinle, 1990.

RILEY, Philip. The guru and the conjurer: aspects of counseling for selfaccess. In: BENSON, Phil; VOLLER, Peter (Eds.). Autonomy and independence in language learning. London: Longman, 1997. p. 114-131.

USHIODA, Autonomy: the role of motivation. Dublin: Authentik, 1996.

VIEIRA, Flávia. Teacher development through inquiry: getting started. In: BARFIELD, Andy; BROWN, Steve (Eds.). Reconstructing autonomy in 
Walkyria Magno e Silva; Edirnelis M. dos Santos

language education: inquiry and innovation. London: Palgrave, 2007. p. 15-29.

Submetido em: 13/09/2014

Aceito em: 09/01/2015

Title: Enhancing autonomy and motivation: the role of the language adviser 